\title{
Pyroelectric Energy Harvesting: With Thermodynamic-Based Cycles
}

\author{
Saber Mohammadi and Akram Khodayari \\ Mechanical Engineering Department, School of Engineering, Razi University, Kermanshah 67149-67346, Iran \\ Correspondence should be addressed to Saber Mohammadi, saberm7@yahoo.com
}

Received 30 November 2011; Revised 31 January 2012; Accepted 2 February 2012

Academic Editor: Mickaël Lallart

Copyright ( $) 2012$ S. Mohammadi and A. Khodayari. This is an open access article distributed under the Creative Commons Attribution License, which permits unrestricted use, distribution, and reproduction in any medium, provided the original work is properly cited.

\begin{abstract}
This work deals with energy harvesting from temperature variations using ferroelectric materials as a microgenerator. The previous researches show that direct pyroelectric energy harvesting is not effective, whereas thermodynamic-based cycles give higher energy. Also, at different temperatures some thermodynamic cycles exhibit different behaviours. In this paper pyroelectric energy harvesting using Lenoir and Ericsson thermodynamic cycles has been studied numerically and the two cycles were compared with each other. The material used is the PMN-25 PT single crystal that is a very interesting material in the framework of energy harvesting and sensor applications.
\end{abstract}

\section{Introduction}

Small, portable, and lightweight power generation systems are currently in very high demand in commercial markets, due to a dramatic increase in the use of personal electronics and communication equipments. The simple way to satisfy these demands is to utilize batteries; however, nonrechargeable batteries are becoming useless upon discharging, and rechargeable batteries require portable power generation units to recharge them. Thus, a portable small-scale power generation system that can either replace batteries entirely or recharge them to extend their lifetime is of considerable interest. There are several different classes of small-scale power generators currently being researched. The power generation technique that is investigated in this study is the thermodielectric power generation system, which is somewhat similar to thermoelectric power generation [1]. Some possible ambient energy sources are thermal energy, solar energy, or mechanical energy. Harvesting energy from such renewable sources has stimulated important research efforts over the past years [2-5]. Thermal energy is a source available everywhere. Also, electronics advances directed the researchers towards completely autonomous microchips embedding their own energy source. Furthermore, proposing self-powered devices opens new application possibilities for the systems with limited accessibility such as biomedical implants, structure embedded microsensors, or safety monitoring devices.

Thermodielectric power generation utilizes the pyroelectric effect to convert heat to useful electricity. Pyroelectricity has been observed in different crystals and ceramics [6]. Materials with high pyroelectric activity or those exhibiting a transition can be used for energy harvesting $[7,8]$. The pyroelectric effect may be used for temperature/heat sensors or energy harvesting; on the contrary the electrocaloric effect may be used for refrigeration devices [9-13]. The pyroelectric effect manifests itself in a polar, capacitive material that has a temperature-dependent electric polarization. It occurs when the material is heated or cooled. The resulting polarization change forces the material to reject or accept electrical charge from its surroundings, based on the direction of temperature change and the orientation of the polarization. Therefore, it can be used in a power generation system to force electrical charge from the power generating material (pyroelectric) to an electrical storage device via heating and cooling.

Initial investigations of thermodielectric power generation have been studied to evaluate the energy conversion properties of various dielectric materials [14-17]. Olsen's 
group studied various power generation cycles that would optimize the power density and thermal efficiency [1822]. Most recently, Ikura's experimental investigation [23] implemented one of Olsen's theoretical operating cycles in a simple thermodielectric converter, demonstrating the ability to generate power with a thermodielectric device.

When considering energy conversion from heat, it is necessary to compare efficiencies with the Carnot cycle efficiency, which is the maximum energy that can be converted for a given temperature variation. However, in the case of pyroelectric energy conversion, a Carnot cycle is not realistic because it is difficult to control successive adiabatic and isothermal conditions. As a consequence, other cycles have to be considered, such as the Ericsson, Olson $[9,22,23]$, or Lenoir cycles. The objective of this study is to further present thermodynamic-based cycles of ferroelectric harvesting energy as an efficient micro-thermodielectric power generator. Therefore, the Lenoir and Ericsson thermodynamic cycles are studied and the results compared with each other numerically. Finally, the thermodynamic cycle simulation results are tested on PMN-25 PT single crystal because of high pyroelectric activity [11, 13, 24].

\section{Thermodynamic Cycles}

Any device that operates in a thermodynamic cycle absorbs thermal energy from a source, rejects a part of it to a sink, and presents the difference between the energy absorbed and energy rejected as work to the surroundings is called a heat engine. A heat engine is, thus, a device that produces work. The mechanism of pyroelectric generator is similar to a heat engine.

When energy is harvested from heat, one should consider at first the classical thermodynamic cycles. What cycle is efficient and is it realistic? What is their efficiency and which parameters are important to optimize the efficiency?

The governing equations of pyroelectric materials are as follows [7]:

$$
\begin{gathered}
d D=\varepsilon_{33}^{\theta} d E+p d \theta, \\
d \Gamma=p d E+c \frac{d \theta}{\theta},
\end{gathered}
$$

where $D, E, \theta$, and $\Gamma$ are electric displacement, electric field, temperature, and entropy, respectively.

The coefficients that are assumed to be constant are defined as in

$$
\varepsilon_{33}^{\theta}=\left.\frac{d D}{d E}\right|_{\theta}, \quad p=\frac{d D}{d \theta}=\frac{d \Gamma}{d E}, \quad c=\left.\frac{d U}{d \theta}\right|_{E},
$$

and also

$$
d \Gamma=\frac{d Q}{\theta}, \quad \eta=\frac{\left|\delta W_{\text {cycle }}\right|}{\left|Q_{h}\right|},
$$

where $Q_{h}$ and $W_{\text {cycle }}$ are the heat taken from the hot reservoir and cycle net work, respectively.

In the following, two different harvesting cycles are presented and their efficiencies compared to the Carnot one.

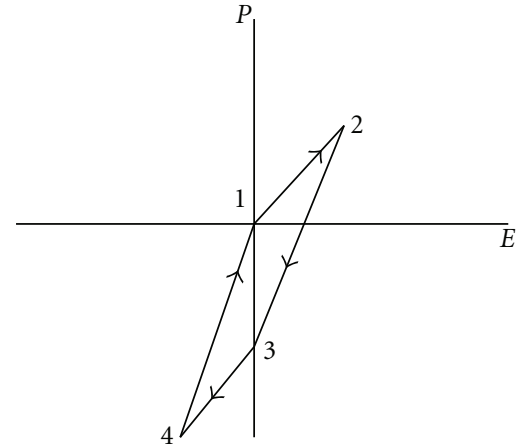

Figure 1: PE thermodynamic Carnot cycle.

\section{Carnot Cycle}

The Carnot cycle is defined as two adiabatic and two isothermal curves on the polarization-electric field (PE) cycle (see Figure 1). It is considered as the optimal energy harvesting cycle whose efficiency is

$$
\eta_{\text {Carnot }}=1-\frac{\theta_{c}}{\theta_{h}},
$$

where $\theta_{c}$ and $\theta_{h}$ are the cold and hot temperatures, respectively. In the first adiabatic increase of the electric field $d \Gamma=$ 0 (path 1-2 in Figure 1) and from (2),

$$
\begin{gathered}
\frac{d \theta}{\theta}=-\frac{p}{c} d E, \\
\ln \left(\frac{\theta_{h}}{\theta_{c}}\right)=-\frac{p}{c} E_{M},
\end{gathered}
$$

where $E_{M}$ is the maximum amplitude of the applied electric field. This equation shows the relation of electric field amplitude with the temperatures ratio. In the isothermal decrease of the electric field $d \theta=0$ (path 2-3),

$$
\begin{gathered}
d \Gamma=\frac{d Q_{h}}{\theta_{h}}=p d E, \\
Q_{h}=-p \theta_{h} E_{M} .
\end{gathered}
$$

The two following steps are similar and are not detailed here (path $4-1$ is similar to $2-3$ and $3-4$ is similar to $1-2$ ). The resulting energy conversion ratio gives

$$
W_{e}=\left(\theta_{h}-\theta_{c}\right) \delta \Gamma=-p E_{M} \frac{\theta_{h}-\theta_{c}}{\theta_{h}} .
$$

In this cycle the conversion ratio does not depend on material properties (5). It depends on the temperature variations.

\section{Ericsson Cycle}

The Ericsson cycle is defined as two constant electric field and two isothermal processes curves on the (PE) cycle (see Figure 2). As it can be seen, the Ericsson cycle starts with applying electric field $E_{1}$ at a temperature $\theta_{c}$ (cold 


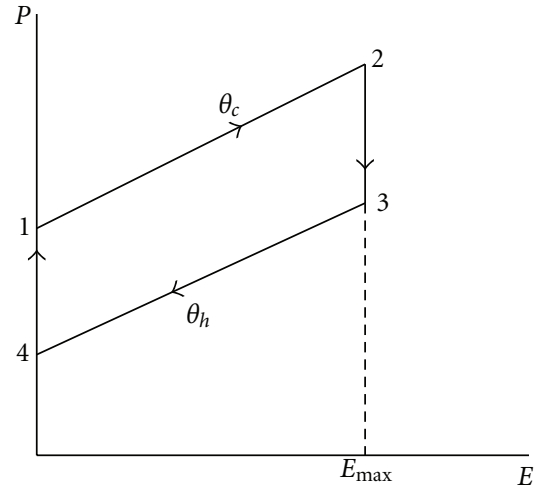

FIgURe 2: PE thermodynamic Ericsson cycle.

temperature). Polarization subsequently increases to the $P_{2}$ value (path 1-2). Then, temperature is increased to $\theta_{h}$ (hot temperature) at constant electric field (path 2-3). Therefore, the polarization of the single crystal decreases to $P_{3}$. Then, with the decrease of the applied electric field from $E_{\max }$ to 0 , the polarization decreases to $P_{4}$ (path 3-4). Temperature is then finally decreased to its initial value, completing the cycle (path 4-1).

Eelectrical and thermal energies can be determined for each segment of cycle. Consequently, we can write

$$
W_{\text {cycle }}=-\left(\theta_{h}-\theta_{c}\right) \int_{0}^{E_{M}} p d E .
$$

The energy taken from the hot temperature reservoir is

$$
Q_{h}=c\left(\theta_{h}-\theta_{c}\right)+\int_{0}^{E_{M}} p \theta_{h} d E
$$

Then, the conversion ratio can be expressed as follows, which defined as the ratio of net electric work to the energy taken from the hot temperature reservoir:

$$
\eta=\frac{\left|W_{\text {cycle }}\right|}{Q_{h}}=\frac{\int_{0}^{E_{M}} p d E}{c+\left(\theta_{h} /\left(\theta_{h}-\theta_{c}\right)\right) \int_{0}^{E_{M}} p d E} .
$$

With the comparison to the Carnot cycle efficiency (5), we obtain

$$
\frac{\eta}{\eta_{\text {Carnot }}}=\frac{\int_{0}^{E_{M}} p d E}{c\left(\theta_{h}-\theta_{c}\right)+\int_{0}^{E_{M}} p \theta_{h} d E}
$$

This ratio decreases with the increase of temperature variations.

\section{Lenoir Cycle}

The Lenoir cycle is an idealized thermodynamic cycle often used to model a pulse jet engine. For the ferroelectric material, The Lenoir cycle is defined as constant polarization, constant electric field, and constant entropy curves on the

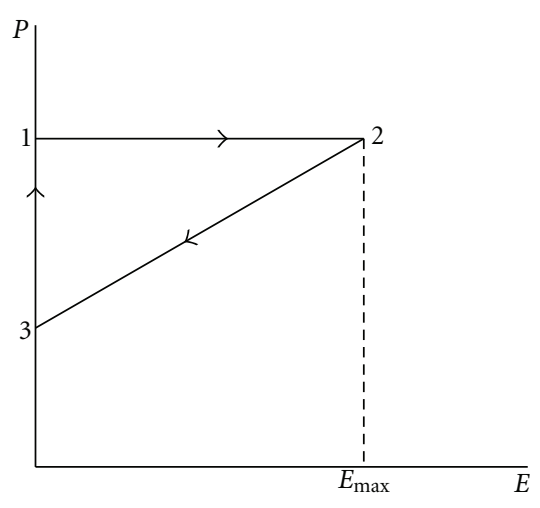

Figure 3: PE Lenoir cycle.

TABle 1

\begin{tabular}{lccc}
\hline Material & $\begin{array}{c}p \\
c_{E}\left(\times 10^{6}\right)\end{array}$ & $\varepsilon / \varepsilon_{0}$ \\
\hline $\begin{array}{l}111 \text { PMN-25PT } \\
\text { (single crystal) }\end{array}$ & 1790 & 2.5 & 961 \\
\hline
\end{tabular}

(PE) cycle (see Figure 3). The first path is the increase of electric field $d D=0$ (path 1-2) and from (1),

$$
\begin{gathered}
\varepsilon d E=-p d \theta, \\
d Q_{12}=p \theta d E+c d \theta,
\end{gathered}
$$

where $d Q_{12}$ is the input thermal heat. In the isentropic path $d \Gamma=0$ (path 2-3) and from (2),

$$
\begin{aligned}
& \frac{d \theta}{\theta}=-\frac{p}{c} d E, \\
& W_{e}=\int E d D .
\end{aligned}
$$

The electrical work can be harvested in this step (15). In the constant electric field $d E=0$ (path 3-1) and from (1) and(2)

$$
\begin{gathered}
d D=p d \theta, \quad d \Gamma=c \frac{d \theta}{\theta}, \\
Q_{31}=c\left(\theta_{3}-\theta_{1}\right),
\end{gathered}
$$

where $Q_{31}$ is the outgoing heat from the material.

\section{Results and Discussions}

In this section, we investigate the simulation results of energy harvesting for each cycle as a function of electric field and temperature. The PMN-25PT single crystal has been selected and its properties are given in Table 1 [10].

Figure 4 presents the harvested energy as a function of electric field. The harvested energy increases nonlinearly in relation to electric field. Its value using the Ericsson cycle is more than the Lenoir cycle. Harvested energies are approximately the same in low electric fields. The harvested energy for Lenoir cycle is $17 \mathrm{~mJ} / \mathrm{cm}^{3}$ and for the Ericsson cycle is $35.5 \mathrm{~mJ} / \mathrm{cm}^{3}$ at $2 \mathrm{kV} / \mathrm{mm}$ electric field. 
TABLE 2: Some comparisons between two cycles at $2 \mathrm{~V} / \mathrm{m}$ of the electric field.

\begin{tabular}{|c|c|c|c|c|}
\hline Cycle & $\begin{array}{l}\text { Harvested energy } \\
\left(\mathrm{mJ} / \mathrm{cm}^{3}\right)\end{array}$ & Efficiency $\eta \%$ & $\begin{array}{l}\text { Efficiency related to the } \\
\text { Carnot cycle } \eta / \eta_{\text {Carnot }} \%\end{array}$ & $\begin{array}{c}\text { Harvested energy and initial } \\
\text { temperature relationship }\end{array}$ \\
\hline Ericsson & 35 & 0.15 & 4.6 & $\begin{array}{l}\text { Harvested energy decreased with } \\
\text { increase of initial temperature } \\
\text { (completely dependent) }\end{array}$ \\
\hline Lenoir & 17 & 0.07 & 0.7 & Independent \\
\hline
\end{tabular}

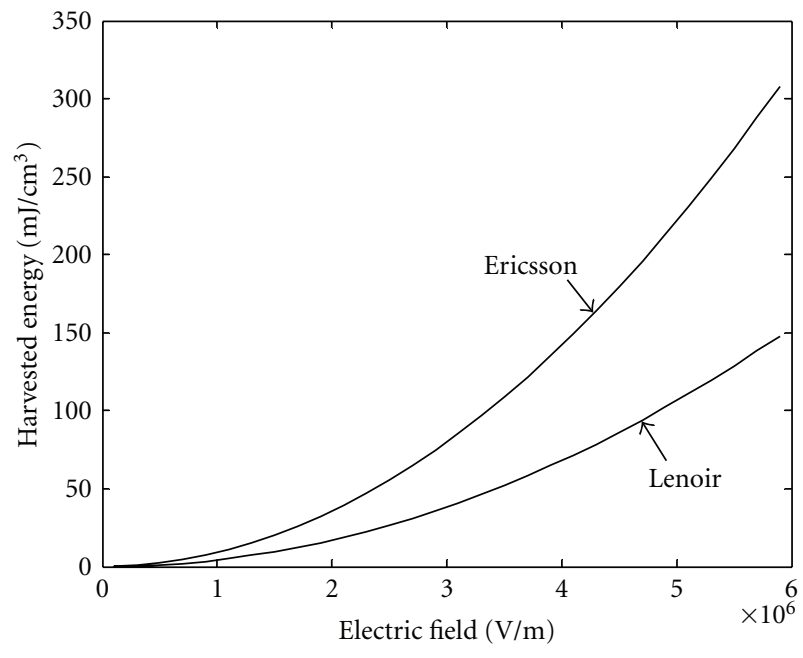

Figure 4: Harvested energy as a function of electric field amplitude.

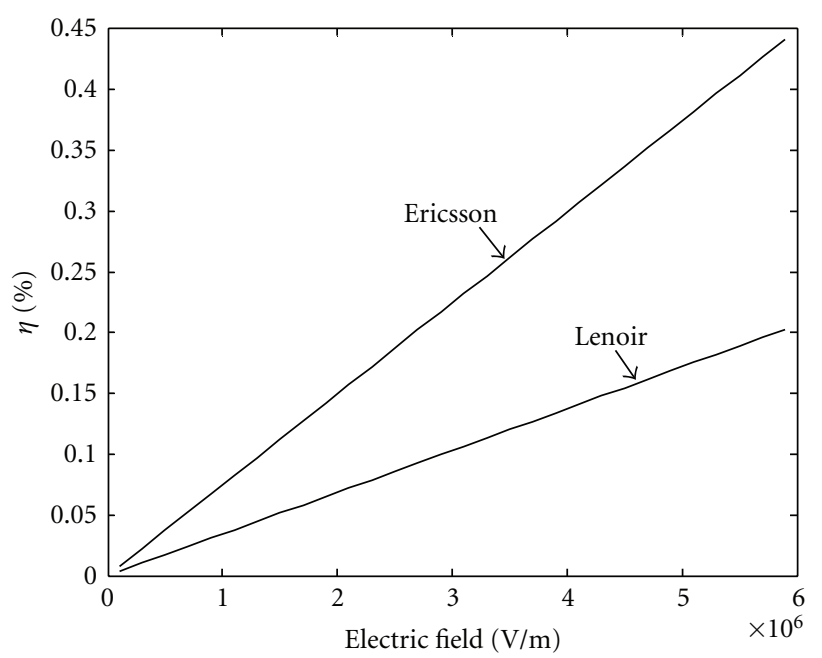

FIGURE 5: Efficiency of different cycles as a function of electric field amplitude.

Figure 5 shows the efficiency versus the electric field variations. Efficiency is defined as the harvested energy divided by the heat transferred from the hot zone to the sample. Furthermore, it is directly proportional to the amplitude of the electric field. Efficiency could be greatly improved for much higher electric fields.

Figure 6 shows the efficiency related to the Carnot one versus the electric field variations. The increase rate of this

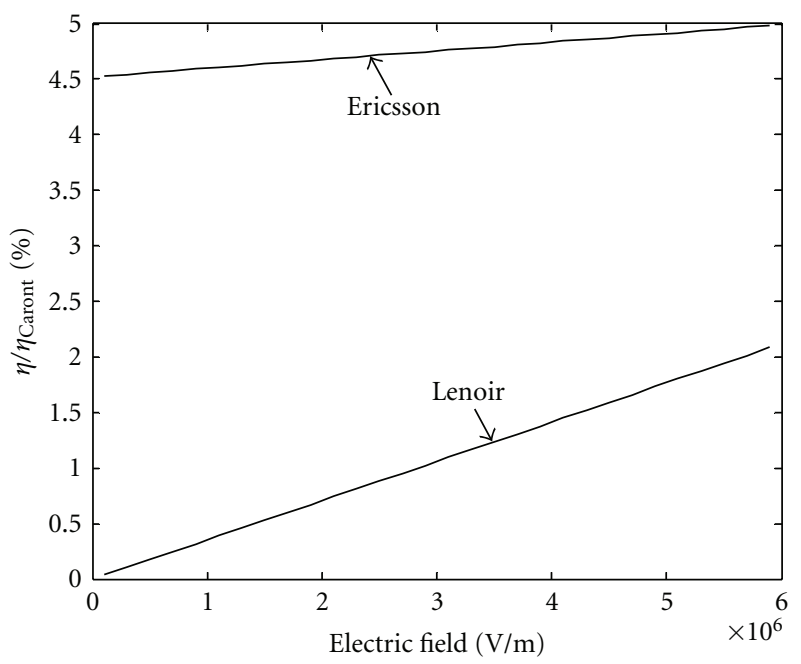

FIGURE 6: Efficiencies related to the Carnot cycle as a function of electric field amplitude.

ratio for the Lenoir cycle is more than the one for the Ericsson cycle.

Figure 7 shows the harvested energy as a function of initial temperature (low temperature at the thermodynamic cycle). Initial temperatures are $\theta_{c}$ in the Ericsson cycle and $\theta_{1}$ in the Lenoir cycle, respectively. It is observed that harvested energies for the Lenoir cycle at various temperatures are the same but they decrease for the Ericsson cycle. It is observed that the Lenoir cycle is not dependent on the initial temperature. This means that this cycle can be used at any temperature condition. It is a good advantage in relation to other cycles whose efficiencies depend on the temperature conditions. Table 2 represents some comparisons between two cycles at $2 \mathrm{~V} / \mathrm{m}$ of the electric field.

\section{Conclusions}

The feasibility of energy harvesting from heat using pyroelectric materials has been studied, which may be of great interest compared to thermoelectric conversion. The Lenoir-based thermodynamic pyroelectric energy harvesting cycle has been compared with the Ericsson one. The cycles were tested on PMN-25PT single crystal. The thermodielectric power generation devices can be useful for portable applications that need a small, low-weight power generator. For electric power generation, cycling of the thermodielectric material temperature requires an unsteady heat exchange system. It was shown that the Lenoir cycle can be used at any 


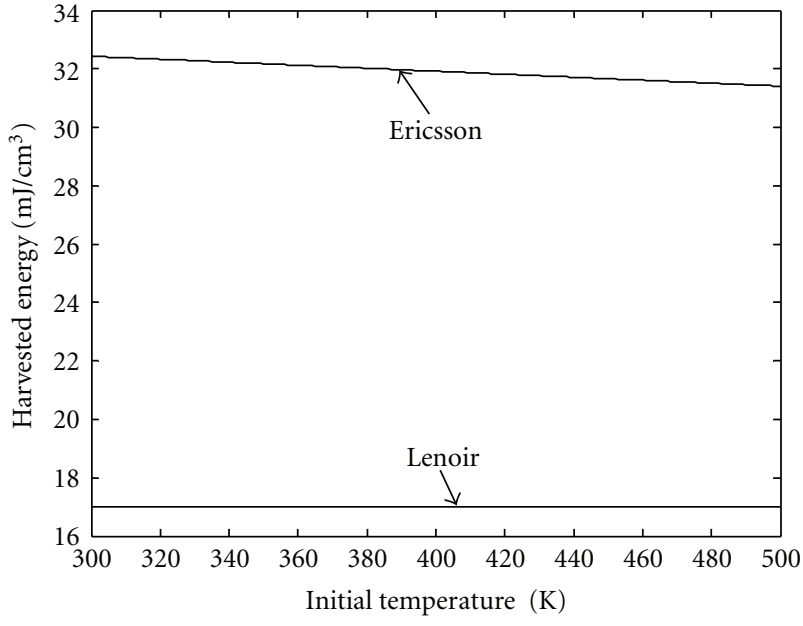

FIGURE 7: Harvested energy as a function of initial temperature.

temperature condition because it is not dependent on the initial temperature (low temperature at the thermodynamic cycle). Although it has low efficiency in relation to other cycles it has a good advantage that it can be used at any temperature condition in relation to other cycles whose efficiencies depend on the temperature conditions. If the modification has been done on the Lenoir cycle, it can be the interesting cycle in this field.

\section{References}

[1] G. S. Nolas, Thermoelectrics: Basic Principles and New Materials Development, Springer, Berlin, Germany, 2001.

[2] R. Want, K. I. Farkas, and C. Narayanaswami, "Energy harvesting and conservation," IEEE Pervasive Computing, vol. 4, no. 1, pp. 14-17, 2005.

[3] S. Roundy, E. S. Leland, J. Baker et al., "Improving power output for vibration-based energy scavengers," IEEE Pervasive Computing, vol. 4, no. 1, pp. 28-36, 2005.

[4] E. Lefeuvre, A. Badel, C. Richard, L. Petit, and D. Guyomar, "A comparison between several vibration-powered piezoelectric generators for standalone systems," Sensors and Actuators A, vol. 126, no. 2, pp. 405-416, 2006.

[5] A. Badel, A. Benayad, E. Lefeuvre, L. Lebrun, C. Richard, and D. Guyomar, "Single crystals and nonlinear process for outstanding vibration-powered electrical generators," IEEE Transactions on Ultrasonics, Ferroelectrics and Frequency Control, vol. 53, no. 4, pp. 673-683, 2006.

[6] L. Kouchachvili and M. Ikura, "Pyroelectric conversion-effects of $\mathrm{P}(\mathrm{VDF}-\mathrm{TrFE})$ preconditioning on power conversion," Journal of Electrostatics, vol. 65, no. 3, pp. 182-188, 2007.

[7] A. Khodayari, S. Pruvost, G. Sebald, D. Guyomar, and S. Mohammadi, "Nonlinear pyroelectric energy harvesting from relaxor single crystals," IEEE Transactions on Ultrasonics, Ferroelectrics and Frequency Control, vol. 56, no. 4, pp. 693698, 2009.

[8] D. Guyoniar, S. Pruvost, and G. Sebald, "Energy harvesting based on FE-FE transition in ferroelectric single crystals," IEEE Transactions on Ultrasonics, Ferroelectrics and Frequency Control, vol. 55, no. 2, Article ID 4460862, pp. 279-285, 2008.

[9] A. Khodayari and S. Mohammadi, "Solid-state cooling line based on the electrocaloric effect," IEEE Transactions on
Ultrasonics, Ferroelectrics and Frequency Control, vol. 58, no. 3, pp. 503-508, 2011.

[10] G. Sebald, L. Seveyrat, D. Guyomar, L. Lebrun, B. Guiffard, and S. Pruvost, "Electrocaloric and pyroelectric properties of $0.75 \mathrm{~Pb}\left(\mathrm{Mg}_{1 / 3} \mathrm{Nb}_{2 / 3}\right) \mathrm{O}_{3}-0.25 \mathrm{PbTiO}_{3}$ single crystals," Journal of Applied Physics, vol. 100, no. 12, Article ID 124112, 2006.

[11] G. Sebald, S. Pruvost, L. Seveyrat, L. Lebrun, D. Guyomar, and B. Guiffard, "Electrocaloric properties of high dielectric constant ferroelectric ceramics," Journal of the European Ceramic Society, vol. 27, no. 13-15, pp. 4021-4024, 2007.

[12] A. Sharma, Z. G. Ban, S. P. Alpay, and J. V. Mantese, "Pyroelectric response of ferroelectric thin films," Journal of Applied Physics, vol. 95, no. 7, pp. 3618-3625, 2004.

[13] D. Guyomar, G. Sebald, B. Guiffard, and L. Seveyrat, "Ferroelectric electrocaloric conversion in $0.75\left(\mathrm{PbMg}_{1 / 3} \mathrm{Nb}_{2 / 3} \mathrm{O}_{3}\right)$ $0.25\left(\mathrm{PbTiO}_{3}\right)$ ceramics," Journal of Physics D, vol. 39, no. 20, article 029, pp. 4491-4496, 2006.

[14] W. H. Clingman and R. G. Moore, "Application of ferroelectricity to energy conversion processes," Journal of Applied Physics, vol. 32, no. 4, pp. 675-681, 1961.

[15] E. Fatuzzo, H. Kiess, and R. Nitsche, "Theoretical efficiency of pyroelectric power converters," Journal of Applied Physics, vol. 37, no. 2, pp. 510-516, 1966.

[16] J. A. Gonzalo, "Ferroelectric materials as energy converters," Ferroelectrics, vol. 11, no. 1, pp. 423-430, 1976.

[17] J. E. Drummond, V. Fargo, J. Ream, H. Reed, J. M. Briuscoe, and D. Brown, "Demonstration of a high power density electro-caloric heat engine," Ferroelectrics, vol. 27, no. 4, pp. 215-218, 1980.

[18] R. B. Olsen, D. A. Bruno, J. M. Briscoe, and E. W. Jacobs, "Pyroelectric conversion cycle of vinylidene fluoridetrifluoroethylene copolymer," Journal of Applied Physics, vol. 57, no. 11, pp. 5036-5042, 1985.

[19] R. Olsen, J. M. Briscoe, D. A. Bruno, and W. F. Butler, "A pyroelectric energy converter which employs regeneration," Ferroelectrics, vol. 38, no. 1-4, pp. 975-978, 1981.

[20] R. B. Olsen and D. Evans, "Pyroelectric energy conversion: hysteresis loss and temperature sensitivity of a ferroelectric material," Journal of Applied Physics, vol. 54, no. 10, pp. 59415944, 1983.

[21] R. B. Olsen, D. A. Bruno, J. M. Briscoe, and J. Dullea, "Cascaded pyroelectric energy converter," Ferroelectrics, vol. 59, no. 3-4, pp. 205-219, 1984.

[22] R. B. Olsen, D. A. Bruno, and J. M. Briscoe, "Pyroelectric conversion cycles," Journal of Applied Physics, vol. 58, no. 12, pp. 4709-4716, 1985.

[23] M. Ikura, "Conversion of low-grade heat to electricity using pyroelectric copolymer," Ferroelectrics, vol. 267, pp. 403-408, 2002.

[24] J. Grindlay, An Introduction to the Phenomenological Theory of Ferroelectricity, Pergamon Press, Oxford, UK, 1970. 

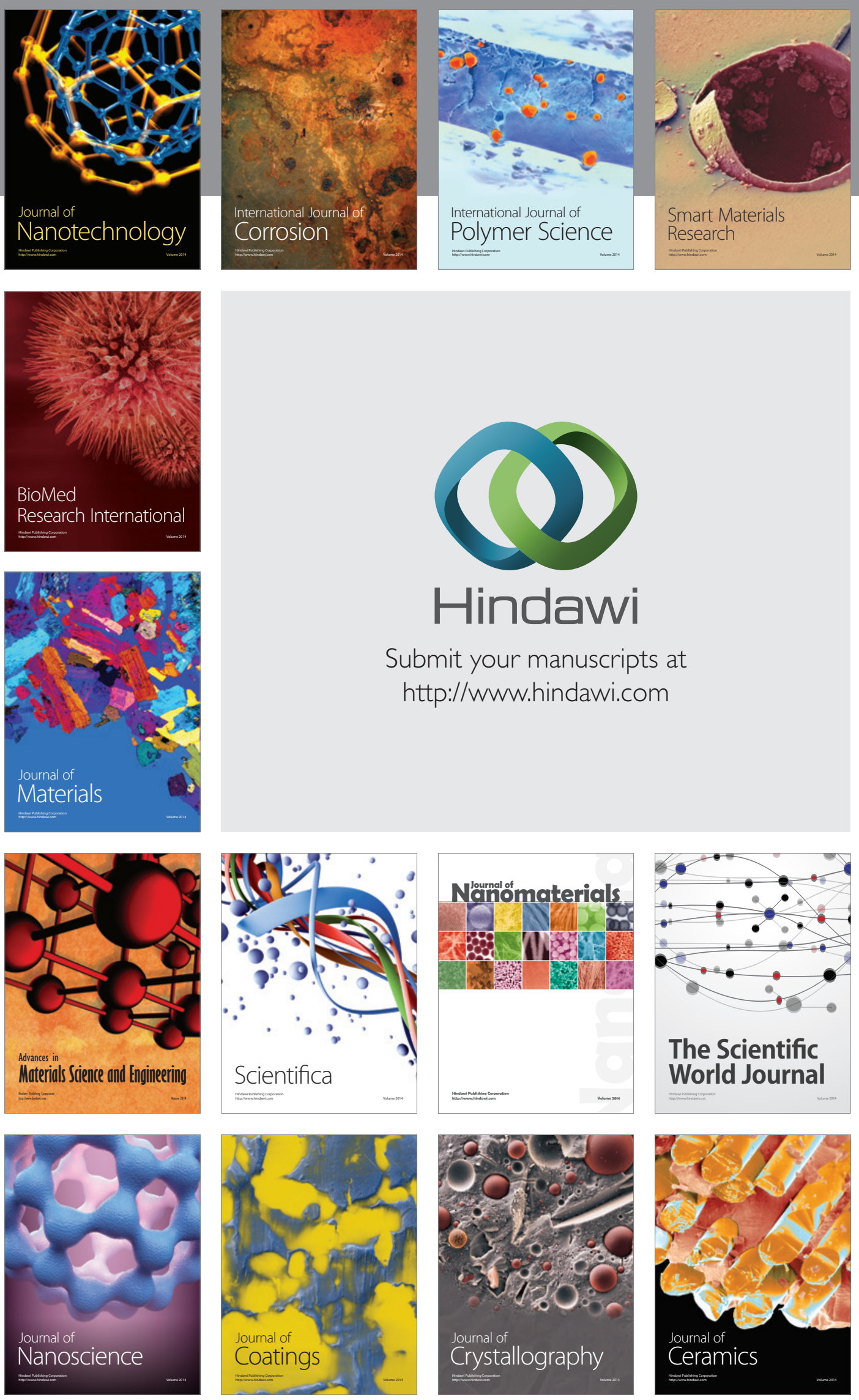

The Scientific World Journal

Submit your manuscripts at

http://www.hindawi.com

\section{World Journal}

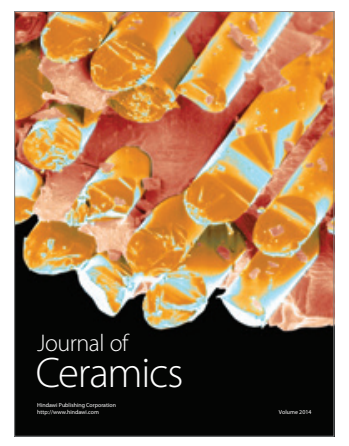

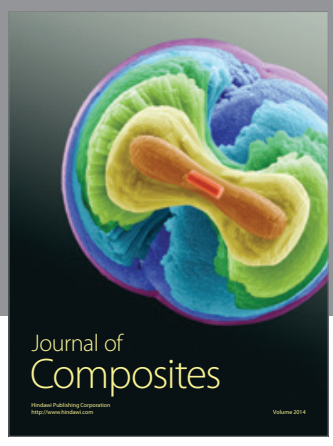
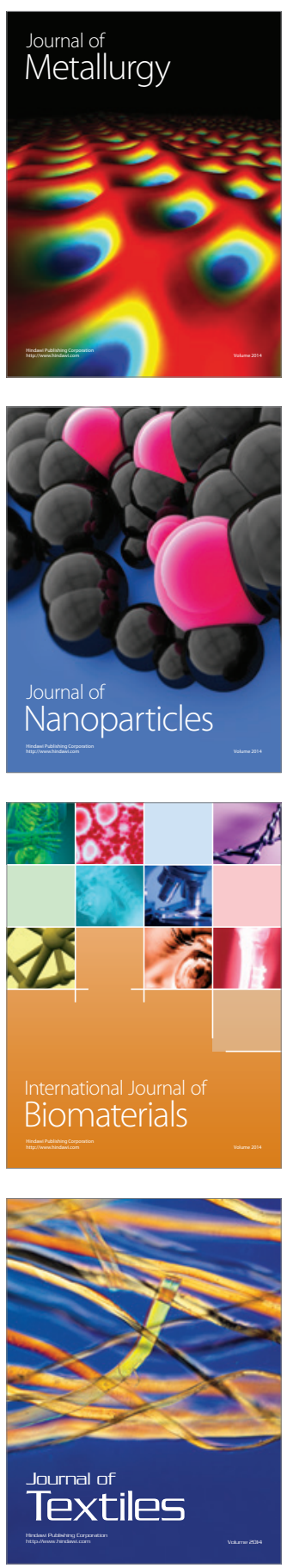